\title{
Desempenho de Cordeiros Alimentados com Silagem de Girassol ou de Milho com Proporções Crescentes de Ração Concentrada
}

\author{
Mauro Sartori Bueno ${ }^{1}$, Evaldo Ferrari Junior ${ }^{1}$, Rosana Aparecida Possenti ${ }^{1}$, Diorande \\ Bianchini $^{2}$, Frederico Fontoura Leinz ${ }^{2}$, Carlos Frederico de Carvalho Rodrigues ${ }^{2}$
}

RESUMO - Foram realizados dois experimentos com o objetivo de avaliar o valor nutritivo de dietas à base de silagens de milho ou de girassol e o desempenho de ovinos alimentados com estas dietas acrescidas de níveis crescentes de concentrado comercial (20, 40 e 60\%). Para avaliação do valor nutritivo e dos coeficientes de digestibilidade aparente dos nutrientes, utilizou-se delineamento em esquema fatorial (2x3), duas silagens e três proporções de ração comercial, com três ovinos por tratamento. Para avaliação do desempenho de cordeiros, o ensaio foi em blocos ao acaso, em esquema fatorial 2x3 (duas silagens e três proporções de ração comercial), com cinco cordeiros por tratamento. Os coeficientes de digestibilidade aparente de MS, MO, FB, ENN, FDN, FDA e de celulose foram menores para as dietas à base de silagem de girassol. As dietas com silagem de milho apresentaram maiores valores de ingestão diária de matéria seca (709,5 x 609,7 g) e ganho diário de peso vivo (181,8 x 108,2 g) e menores de conversão alimentar (3,82 x 5,35 kg de MS/kg de ganho de PV) que as de girassol. As dietas à base de silagem de girassol apresentaram valor nutritivo inferior às de silagem de milho, o que acarretou pior desempenho dos cordeiros. Os animais alimentados com dietas à base de silagem de girassol necessitam de maior quantidade de ração concentrada para obterem desempenho similar aos alimentados com silagem de milho.

Palavras-chave: conversão alimentar, digestibilidade, girassol, ingestão de matéria seca, milho, silagem

\section{Performance of Sheep Fed Sunflower Silage or Corn Silage with Increasing Proportion of Commercial Concentrate}

\begin{abstract}
Two experiments were conduct to evaluate the effect of dietary nutritive value and performance of sheep fed corn- or sunflower silage-based diet with increasing concentrate proportion (20, 40 and 60\%). A factorial design (2x3) was used to evaluate nutritive value and digestibility coefficient of two silages with three concentrate levels and three sheep for each treatment. For lamb performance, a randomized block design in a factorial arrangement (2x3) was used to evaluate lamb performance, with five Suffolk lambs/treatment. Apparent digestibility coefficients of DM, OM, CF, NFE, NDF, ADF and cellulose were smaller for sunflower than for corn silage. Corn silage-based diets showed higher values of daily dry matter intake (709.5 x $609.7 \mathrm{~g})$, daily live weight gains ( 181.8 x $108.2 \mathrm{~g}$ ) and lower values of feed:gain ratio (3.82 x $5.53 \mathrm{~kg}$ DM/kg LW gain) than sunflower silage-based diets. Sunflower silage-based diets showed lower nutritive values than corn silage-based and smaller lamb performance. Lambs fed sunflower silage-based diets need more concentrate ration to obtain performance similar to those fed corn silage-based diets.
\end{abstract}

Key Words: corn, digestibility, feed:gain ratio, intake, silage, sunflower

\section{Introdução}

A silagem de milho apresenta excelentes características como alimento para ruminantes, pois proporciona elevado consumo voluntário e fornece alto teor de nutrientes digestíveis totais (Pereira et al., 1993), o que confere bom desempenho para cordeiros em acabamento (Cunha et al., 2001).

O cultivo do girassol para produção de forragem apresenta algumas características agronômicas favoráveis, como menor exigência hídrica, maior adaptação às distintas condições edafo-climáticas, constituindo-se uma opção para rotação de cultura na safrinha (Gonçalves, 2000).

A silagem de girassol apresenta composição bromatológica distinta da silagem de milho, com teores mais elevados de proteína bruta, de extrato etéreo e de matéria mineral e diferença na composição da parede celular, com valores mais elevados de lignina (Henrique et al., 1998a; Rodrigues et al., 2001; McGuffey \& Schingoethe, 1980; Thomas et al., 1982). Os padrões de fermentação parecem adequados,

\footnotetext{
${ }^{1}$ Pesquisador Científico, Instituto de Zootecnia, C.P. 60, CEP: 13.460-000 - Nova Odessa/SP. E.mail: msbueno@iz.sp.gov.br; ferrari@iz.sp.gov.br

${ }^{2}$ Pesquisador Científico, Unidade de Pesquisa e Desenvolvimento de Itapetininga, C.P. 169, CEP: 18200-000 - Itapetininga/SP. E.mail: upditape@uol.com.br
} 
geralmente com $\mathrm{pH}$ mais elevado que o milho e teores moderados de nitrogênio amoniacal (Gonçalves et al., 2000; Rodrigues et al., 2001).

A silagem de girassol apresentou menores valores de coeficientes de digestibilidade in vitro e de digestibillidade aparente da MS e da FDN que a de milho (Valdez et al., 1988a, b). Mizubuti et al. (2002), ao trabalharem com ovinos, também encontraram valores inferiores para os coeficientes de digestibilidade aparente da fibra em detergente ácido para a silagem de girassol em relação à de milho.

Vacas alimentadas com dietas à base de silagem de girassol apresentaram consumo inferior de MS e produziram menos leite, mas quantidade similar à de vacas alimentadas com dietas à base silagem de milho para leite corrigido a $4 \%$ de gordura (McGuffey \& Schingoethe, 1980).

Não foram encontradas diferenças significativas no consumo voluntário de MS e de energia em ovinos, entre as silagens de girassol e de milho (Almeida et al., 1995), ao passo que Ribeiro et al. (2003) observaram valores de ganho de peso diário mais elevados e de conversão alimentar e consumo voluntário de MS mais baixos, em ovelhas confinadas alimentadas com silagem de girassol em relação à de milho.

O uso de ração concentrada na alimentação de ruminantes é necessário para aumentar a ingestão de energia e de proteína e para atender à maior demanda dos animais em produção. Contudo, pode interferir no consumo voluntário ou na digestibilidade de alguns nutrientes, conforme reportado por Cardoso et al. (2000).

Objetivou-se, com este experimento, avaliar o valor nutritivo de dietas à base de silagens de milho ou de girassol e o desempenho de cordeiros alimentados com estas dietas, acrescidas de níveis crescentes de concentrado comercial.

\section{Material e Métodos}

A presente pesquisa foi realizada nas dependências da Unidade de Pesquisa e Desenvolvimento de Itapetininga, Itapetininga, São Paulo (plantio, confecção das silagens, teste de desempenho ponderal) e na sede (teste de digestibilidade) do Instituto de Zootecnia, APTA - Agência Paulista de Tecnologia dos Agronegócios, Nova Odessa/SP.

Como material para ensilagem, foi utilizado o cultivar de milho LC-34 e o cultivar de girassol
RUMBOSOL - 91. O plantio foi efetuado em linhas distanciadas de $0,80 \mathrm{~m}$, com cinco e quatro plantas por metro linear, respectivamente, para milho e girassol. As duas culturas receberam adubação de $500 \mathrm{~kg} / \mathrm{ha}$ da fórmula 04-14-08 no plantio e cobertura de $250 \mathrm{~kg} / \mathrm{ha}$ de sulfato de amônia aos 45 dias após o plantio.

O ponto de colheita para ensilagem do milho foi efetuado quando os grãos estavam no estádio farináceo e, para o girassol, quando os capítulos encontravam-se voltados para baixo com a parte dorsal na coloração amarelo queimado. As culturas foram colhidas com ensiladeiras tracionadas por trator e acondicionadas em recipientes plásticos com capacidade de, aproximadamente, $200 \mathrm{~kg}$. O material ensilado foi utilizado para o ensaio de digestibilidade aparente com ovinos. Para o experimento de desempenho ponderal com ovinos, as culturas foram colhidas na mesma época e colocadas em silos tipo trincheira, com capacidade de, aproximadamente, $6 \mathrm{t}$.

O material processado permaneceu nos silos por 60 dias e, posteriormente, foi submetido às amostragens e à alimentação animal.

Para avaliação da ingestão voluntária de matéria seca e da digestibilidade aparente, utilizaram-se 18 borregas mestiças Ile de France, vermifugadas, com 10 meses de idade e peso vivo médio de $30,5 \mathrm{~kg}$, alojadas em gaiolas de estudos metabólicos equipadas com coletor e separador de fezes e urina. Após 14 dias de adaptação ao ambiente e à dieta, mensurouse o consumo voluntário por sete dias, pesando-se alimento oferecido e suas sobras. Após este período, o alimento volumoso oferecido foi padronizado para $90 \%$ da ingestão voluntária observada no período anterior e efetuou-se, na seqüência, a coleta total de fezes, por sete dias, pela manhã, segundo Schneider \& Flatt (1975). Coletaram-se diariamente amostras do material oferecido e suas sobras.

Os tratamentos consistiram em dietas à base de silagem de milho ou de girassol, com três proporções distintas de ração concentrada na matéria seca total consumida (20, 40 e 60\%). A ração concentrada comercial utilizada foi composta por milho e aveia em grãos laminados, por farelos de soja e de algodão e por minerais na forma granulada (Tabela 1).

O delineamento experimental foi completamente ao acaso, em esquema fatorial do tipo $2 \mathrm{x} 3$ (duas silagens e três proporções de ração comercial), com três ovinos por tratamento, utilizando-se o procedimento GLM do SAS (1990) para a comparação das médias. Avaliaram-se neste estudo, os coeficientes 
de digestibilidade de matéria seca (MS), de matéria orgânica (MO), proteína bruta (PB), fibra bruta (FB), extrato etéreo (EE), extrativo não-nitrogenado (ENN), de fibra em detergente neutro (FDN), fibra em detergente ácido (FDA), celulose, hemicelulose e de lignina das dietas e calculou-se o teor de nutrientes digestíveis totais (NDT).

As médias das variáveis foram comparadas por análise de variância e os níveis de concentrado submetidos à análise de regressão.

Para o estudo do desempenho ponderal de ovinos, foram utilizados 30 cordeiros machos não-castrados da raça Suffolk, recém-desmamados, vermifugados, com idade de $61 \pm 3$ dias e peso vivo inicial de 15,6 $\pm 1,8 \mathrm{~kg}$.

Os animais foram mantidos em gaiolas individuais com piso ripado de $1,5 \mathrm{~m}^{2}$ e alimentados duas vezes ao dia com silagem de milho ou de girassol ad libitum e ração concentrada comercial, nas proporções de 20, 40 e $60 \%$ da matéria seca total, durante 56 dias, após 14 dias de adaptação.

Os alimentos oferecidos e suas sobras foram pesados diariamente; os animais, por sua vez, foram pesados no início, no final e em intervalos de 14 dias, pela manhã, antes do fornecimento da alimentação. Foram calculados o ganho de peso vivo diário (em g) e a conversão alimentar (kg de matéria seca ingerida/kg ganho de peso vivo).

O ensaio foi em blocos ao acaso, em esquema fatorial 2x3 (duas silagens e três proporções de ração comercial), com cinco cordeiros por tratamento. As variáveis foram submetidas à análise de variância, incluindo no modelo o efeito do tipo de silagem, da proporção de ração concentrada e de sua interação, o bloco e o erro experimental. As variáveis ganho de peso vivo diário e conversão alimentar foram transformadas em $\log (x+10)$.

As comparações entre silagens (efeito qualitativo) foram feitas pelo teste de médias (teste $F$ ) e as comparações entre as proporções de ração concentrada (efeito quantitativo) foram submetidas à análise de regressão, por intermédio do SAS (1990).

\section{Resultados e Discussão}

A análise da composição dos alimentos (Tabela 1) indicou que a silagem de girassol possui características químicas distintas às de silagem de milho, com conteúdos mais baixos de matéria seca e de matéria orgânica, e, por outro lado, valores mais elevados de proteína bruta, de matéria mineral e de extrato etéreo. A silagem de girassol apresentou, também, diferenças acentuadas na composição da parede celular, com menor valor de FDN e maiores valores de FDA e de lignina que a silagem de milho, corroborando os resultados reportados por McGuffey \& Shingoethe (1980), Henrique et al. (1998a) e Rodrigues et al. (2001).

Os coeficientes de digestibilidade aparente dos nutrientes das dietas e a ingestão voluntária de matéria seca, expressos em porcentagem do peso vivo ou em gramas de matéria seca por unidade de tamanho metabólico, são descritos na Tabela 2.

Não houve diferença significativa entre as silagens para ingestão voluntária de matéria seca, o que

Tabela 1 - Teores médios de matéria seca (MS), matéria orgânica (MO), proteína bruta (PB), extrato etéreo (EE), matéria mineral (MM), extrativo não-nitrogenado (ENN), fibra em detergente neutro (FDN), fibra em detergente ácido (FDA), hemicelulose (HEM), celulose (CEL) e de lignina (LIG) das silagens e ração comercial

Table 1 - Average contents of dry matter (DM), organic matter (OM), crude protein (CP), ether extract (EE), ash (ASH), nitrogen free extract (NFE), neutral detergent fiber (NDF), acid detergent fiber (ADF), hemicellulose (HEM), cellulose (CEL), lignin $(L I G)$ of silages and concentrate

\begin{tabular}{|c|c|c|c|c|c|c|c|c|c|c|c|}
\hline $\begin{array}{l}\text { Alimentos } \\
\text { Feed }\end{array}$ & $\begin{array}{c}\text { MS } \\
D M \\
\%\end{array}$ & $\begin{array}{l}\text { MO } \\
\text { OM }\end{array}$ & $\begin{array}{l}\mathrm{PB} \\
C P\end{array}$ & $\begin{array}{l}\mathrm{EE} \\
\mathrm{EE}\end{array}$ & $\begin{array}{l}\text { MM } \\
\text { ASH }\end{array}$ & $\begin{array}{c}\text { ENN } \\
N F E \\
\% \mathrm{M}\end{array}$ & $\begin{array}{l}\text { FDN } \\
N D F \\
\% D M)\end{array}$ & $\begin{array}{l}\text { FDA } \\
A D F\end{array}$ & HEM & CEL & LIG \\
\hline $\begin{array}{l}\text { Silagem milho } \\
\text { Corn silage }\end{array}$ & $34,6^{\mathrm{a}}$ & $94,2^{\mathrm{a}}$ & $9,4^{\mathrm{b}}$ & $3,2^{b}$ & $5,8^{b}$ & $56,7^{a}$ & $62,6^{\mathrm{a}}$ & $31,9^{b}$ & $30,3^{\mathrm{a}}$ & $27,0^{\mathrm{b}}$ & $3,7^{\mathrm{b}}$ \\
\hline $\begin{array}{l}\text { Silagem girassol } \\
\text { Sunflower silage }\end{array}$ & $22,0^{b}$ & $85,4^{b}$ & $11,6^{\mathrm{a}}$ & $10,1^{\mathrm{a}}$ & $14,7^{\mathrm{a}}$ & $37,6^{b}$ & $44,3^{b}$ & $42,7^{\mathrm{a}}$ & $1,5^{\mathrm{b}}$ & $31,9^{\mathrm{a}}$ & $9,4^{\mathrm{a}}$ \\
\hline CV (\%) & 3,13 & 3,26 & 4,15 & 14,62 & 8,31 & 3,63 & 2,32 & 4,29 & 13,39 & 4,86 & 6,59 \\
\hline $\begin{array}{l}\text { Concentrado } \\
\text { Concentrate }\end{array}$ & 87,1 & 92,5 & 20,4 & 5,3 & 7,5 & 58,7 & 33,2 & 9,8 & 23,9 & 7,7 & 1,7 \\
\hline
\end{tabular}

${ }^{1}$ Médias seguidas por letras distintas, na coluna, diferem $(P<0,05)$ entre si pelo teste $F$.

${ }^{1}$ Means followed by different letters, in the column, differ $(P<.05)$ by $F$ test.

R. Bras. Zootec., v.33, n.6, p.1942-1948, 2004 (Supl. 2) 
Tabela 2 - Ingestão voluntária de matéria seca por unidade de tamanho metabólico (IV/UTM) ou em porcentagem do peso vivo (IV\%PV), coeficientes de digestibilidade aparente médios (CDA, \%) de borregas alimentados com silagem de milho (SM) ou de girassol (SG) com proporções crescentes de ração concentrada (20, 40 e $60 \%$ ), coeficientes de variação $(\mathrm{CV})$ e coeficientes de determinação $\left(\mathrm{R}^{2}\right)$

Table 2 - Dry matter intake in relation to the metabolic weight (DMIMW) or percentage of live weight (PLW), average apparent digestibility coefficient (ADC, \%) of sheep fed corn- (CS) or sunflower (SS) silage-based diet with increasing concentrate proportions (20, 40 and 60\%), coefficients of variation (CV) and coefficients of determination $\left(R^{2}\right)$

\begin{tabular}{|c|c|c|c|c|c|c|c|c|c|c|c|c|}
\hline $\begin{array}{l}\text { Trat. } \\
\text { Treat }\end{array}$ & $\begin{array}{c}\text { IV } \\
\text { UTM } \\
D M I \\
M W\end{array}$ & $\begin{array}{c}\mathrm{IV} \\
\% \mathrm{PV} \\
P L W\end{array}$ & $\begin{array}{c}\text { CDA } \\
\text { MS } \\
A D C \\
D M\end{array}$ & $\begin{array}{c}\text { CDA } \\
\text { MO } \\
A D C \\
O M\end{array}$ & $\begin{array}{c}\text { CDA } \\
\text { PB } \\
A D C \\
C P\end{array}$ & $\begin{array}{c}\text { CDA } \\
\text { FB } \\
A D C \\
C F\end{array}$ & $\begin{array}{c}\text { CDA } \\
E E \\
A D C \\
E E\end{array}$ & $\begin{array}{l}\text { CDA } \\
\text { ENN } \\
A D C \\
N F E\end{array}$ & $\begin{array}{l}\text { CDA } \\
\text { FDN } \\
A D C \\
N D F\end{array}$ & $\begin{array}{l}\text { CDA } \\
\text { FDA } \\
A D C \\
A D F\end{array}$ & $\begin{array}{c}\text { CDA } \\
\text { CEL } \\
A D C \\
C E L\end{array}$ & $\begin{array}{l}\text { NDT\% } \\
\text { TDN\% }\end{array}$ \\
\hline $\begin{array}{l}\text { SM } \\
C S\end{array}$ & 74,0 & 3,14 & 69,5 & 71,2 & 72,8 & 53,9 & 90,4 & 74,4 & 60,2 & 49,7 & 57,4 & 71,3 \\
\hline $\begin{array}{l}\text { SG } \\
\text { SS }\end{array}$ & 77,7 & 3,32 & 63,2 & 64,0 & 71,8 & 41,4 & 91,0 & 64,1 & 39,5 & 39,8 & 51,3 & 66,6 \\
\hline 20 & 63,8 & 2,76 & 63,0 & 64,0 & 66,7 & 46,3 & 90,4 & 66,1 & 47,7 & 46,2 & 56,6 & 65,4 \\
\hline 40 & 76,6 & 3,27 & 66,5 & 67,7 & 73,7 & 51,3 & 91,1 & 68,1 & 49,9 & 45,7 & 54,1 & 69,0 \\
\hline $\begin{array}{l}60 \\
\mathrm{CV} \%\end{array}$ & $\begin{array}{r}87,0 \\
7,8\end{array}$ & $\begin{array}{l}3,66 \\
6,9\end{array}$ & $\begin{array}{r}69,7 \\
7,4\end{array}$ & $\begin{array}{r}71,2 \\
8,3\end{array}$ & $\begin{array}{r}76,5 \\
6,5\end{array}$ & $\begin{array}{r}45,5 \\
8,5\end{array}$ & $\begin{array}{r}90,6 \\
7,8\end{array}$ & $\begin{array}{r}73,5 \\
9,7\end{array}$ & $\begin{array}{l}52,0 \\
12,1\end{array}$ & $\begin{array}{l}42,2 \\
11,1\end{array}$ & $\begin{array}{r}52,2 \\
9,7\end{array}$ & $\begin{array}{r}72,6 \\
7,5\end{array}$ \\
\hline Silag. & ns. & ns. & $* *$ & $* *$ & ns. & $* *$ & ns. & $* *$ & $* *$ & $* *$ & $* *$ & $* *$ \\
\hline $\begin{array}{l}\text { Conc. } \\
\mathrm{R}^{2}\end{array}$ & $\begin{array}{l}* * \\
0,63\end{array}$ & $\begin{array}{l}* * \\
0,57\end{array}$ & $\begin{array}{l}* * \\
0,32\end{array}$ & $\begin{array}{l}* * \\
0,31\end{array}$ & $\begin{array}{l}* * \\
0,75\end{array}$ & $\begin{array}{r}\text { ns. } \\
\text { - }\end{array}$ & $\begin{array}{r}\text { ns. } \\
-\end{array}$ & $\begin{array}{l}* \\
0,30\end{array}$ & $\begin{array}{r}\text { ns. } \\
-\end{array}$ & ns. & ns. & $\begin{array}{l}* * \\
0,39\end{array}$ \\
\hline
\end{tabular}

ns - não-significativo $(P>0,05) ;{ }^{*}(P<0,05) ; * *(P<0,01)$

ns - not significant $(P>.05) ;{ }^{*}(P<.05) ; * *(P<.01)$.

confirma os relatos de Almeida et al. (1995) e Mizubuti et al. (2002), embora Ribeiro et al. (2003) tenham encontrado maior consumo para ovelhas alimentadas com silagem de girassol.

O aumento da proporção de ração concentrada na dieta dos animais proporcionou aumento linear significativo para consumo. Os valores encontrados são adequados para essa categoria de animais (NRC, 1985), sendo similares aos registrados por Ribeiro et al. (2003) e superiores aos relatados por Henrique et al. (1998b), que testaram silagem de milho ou girassol como alimento exclusivo.

Os coeficientes de digestibilidade aparente (CDA) de matéria seca e de matéria orgânica mostraram diferenças $(\mathrm{P}<0,01)$ entre as silagens e foram mais elevados para a silagem de milho. O aumento da proporção de ração concentrada na dieta dos animais ocasionou aumentos lineares significativos no coeficiente de digestibilidade destas frações e maior digestibilidade destas frações na ração concentrada.

Os CDA da proteína bruta foram elevados e similares entre as silagens. Todavia, foram afetados pelo aumento na proporção de ração concentrada, mostrando aumento linear significativo.

Os CDA do extrato etéreo não apresentaram diferença $(\mathrm{P}>0,05)$ entre silagens, apesar do teor muito mais elevado desta fração na silagem de girassol, e não foram afetados pela proporção de ração na dieta, evidenciando que o elevado teor de extrato etéreo da silagem de girassol é muito bem aproveitado pelos animais.

O CDA do extrativo não-nitrogenado sofreu diferença significativa entre tipos de silagens, com menor valor para a silagem de girassol, corroborando os resultados de Henrique et al. (1998b), e avanço linear significativo com o aumento da ração concentrada. Provavelmente, o amido representa grande proporção desta fração na silagem de milho, o que explica seu maior valor nesta silagem.

Os carboidratos estruturais das dietas apresentaram diferenças significativas somente com relação às silagens utilizadas e não sofreram efeito da proporção de ração concentrada. Os coeficientes de digestibilidade de fibra bruta, fibra em detergente neutro, fibra em detergente ácido e de celulose foram inferiores para a silagem de girassol, o que pode ser decorrente de seu elevado teor de lignina, similar aos dados reportados por Henrique et al. (1998 a) e Valdez et al. (1988a), Valdez et al. (1988b), e de seu baixo teor de hemicelulose. O elevado teor de extrato etéreo pode, também, ter influenciado negativamente a digestibilidade desta fração, pois, segundo o AFRC (1993), os óleos não fornecem adenosina-tri-fosfato para o crescimento dos microorganismos ruminais e, assim, níveis elevados desta fração nutritiva podem diminuir a digestibilidade da fibra. 
A concentração de nutrientes digestíveis totais das dietas diferiu $(\mathrm{P}<0,01)$ entre as silagens, comprovando valor mais elevado para a silagem de milho e aumento linear significativo com o aumento da proporção de ração concentrada. Este fato evidencia a estrutura da parede celular e o tipo de energia armazenada dos vegetais que deram origem às silagens. $\mathrm{O}$ milho armazena energia prioritariamente em forma de amido e possui a parede celular menos lignificada e com maior quantidade de hemicelulose (Tabela 1), de elevada degradabilidade ruminal. O girassol, por sua vez, armazena energia em forma de óleo e sua parede celular é constituída basicamente de lignocelulose, de menor degradabilidade ruminal.

O desempenho de cordeiros em crescimento alimentados com as diferentes dietas está descrito na Tabela 3 e as curvas de crescimento, nas Figuras 1 e 2.

As curvas de crescimento, dos cordeiros exibem padrões distintos, em função da dieta consumida, o que produziu diferenças $(\mathrm{P}<0,01)$ nos pesos finais. As diferentes proporções de ração concentrada evidenciaram curvas de crescimento com formato muito distinto. A dieta à base de silagem de girassol com pequena proporção de ração concentrada propiciou desempenho insatisfatório, que pode ser averi- guado pelo formato da curva de pesos. Nas dietas à base de silagem de girassol, foram necessárias maiores quantidades de ração concentrada para se obter ganho de peso satisfatório.

A ingestão média diária de matéria seca, o ganho médio diário e a conversão alimentar apresentaram efeito estatístico para o tipo de silagem $(\mathrm{P}<0,01)$ e para a proporção de concentrado $(\mathrm{P}<0,01)$ e houve interação significativa $(\mathrm{P}<0,05)$ entre os fatores avaliados (Tabela 3).

Houve diferença significativa para ingestão média diária de MS entre as silagens somente para os animais alimentados com a menor proporção de ração concentrada (20\%), o que pode ser atribuído às diferenças no valor nutritivo das silagens (Tabelas 1 e 2). O maior conteúdo de ligno-celulose na parede celular presente na silagem de girassol (Tabela 1) acarretou provável redução no esvaziamento ruminal, desfavorecendo a ingestão voluntária (Mertens, 1994). Nas dietas com maiores proporções de ração concentrada, não foram evidenciadas diferenças significativas para esta variável, possivelmente em virtude de melhor condição ruminal.

O incremento na proporção de ração concentrada resultou em aumento linear na ingestão diária de

Tabela 3 - Ingestão média diária de matéria seca (IDMS, g), ganho médio diário de peso vivo (GMD, g), conversão alimentar (CA, kg MS ingerida/kg de ganho de peso vivo) de cordeiros em crescimento e coeficiente de variação (CV)

Table 3 - Daily dry matter intake (IDMS, g), average daily live weight gain (GMD, g), feed:gain ratio (CA, kg DM/kg live weight gain) of growing lambs and coefficient of variation (CV)

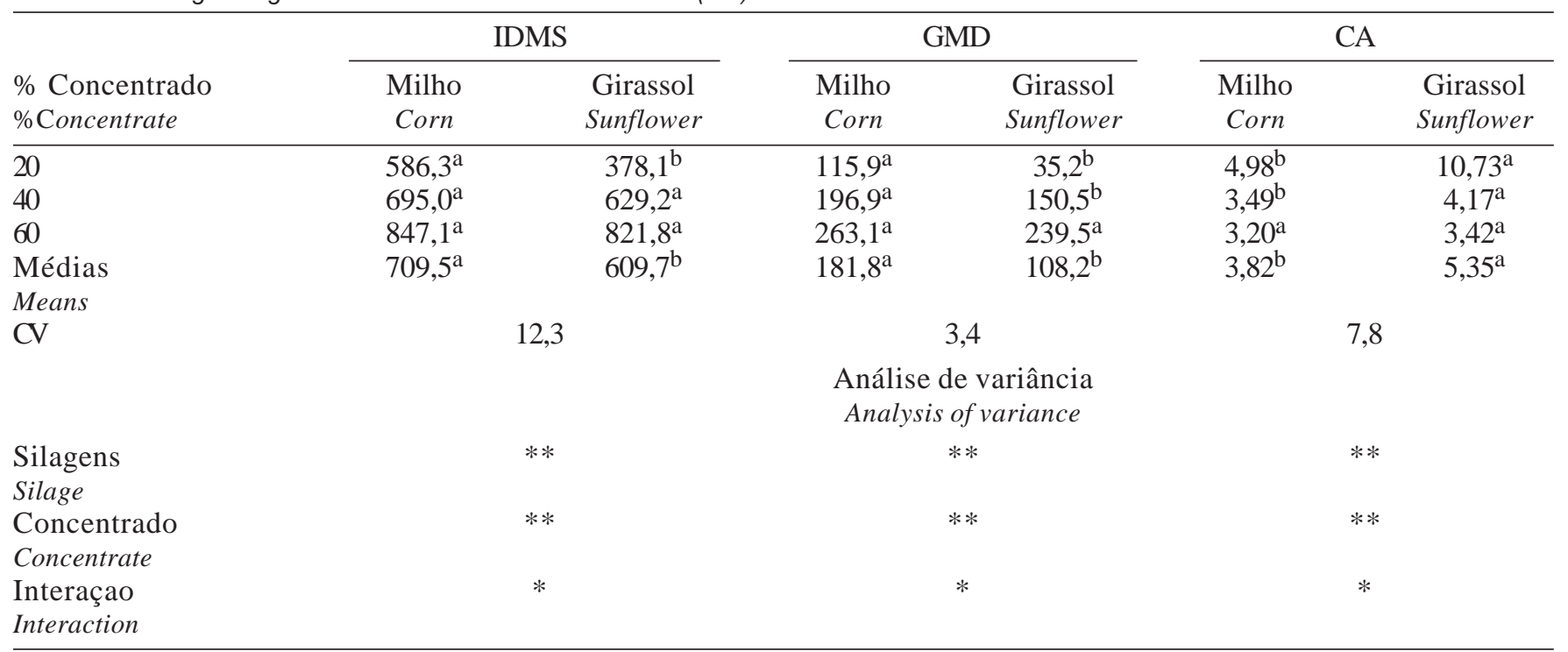

Médias seguidas por letras distintas nas linhas dentro de cada variável diferem entre si pelo teste $F(P<0,05)$.

* $(\mathrm{P}<0,05)$; ** $(\mathrm{P}<0,01)$.

${ }^{1}$ Means followed by different letters within rows into each variable differ by $F$-test $(P<.05)$.

* $(P<.05) ; * *(P<.01)$.

R. Bras. Zootec., v.33, n.6, p.1942-1948, 2004 (Supl. 2) 


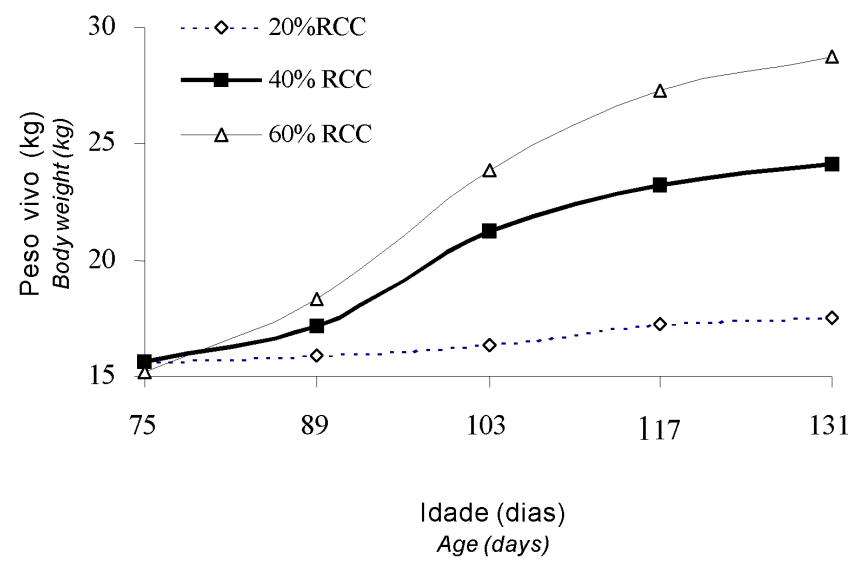

Figura 1 - Crescimento de cordeiros alimentados com dietas à base de silagem de girassol com distintas proporções de ração concentrada comercial (RCC).

Figure 1 - Growth of lambs fed sunflower-silage based diets with increasing concentrate proportions (RCC).

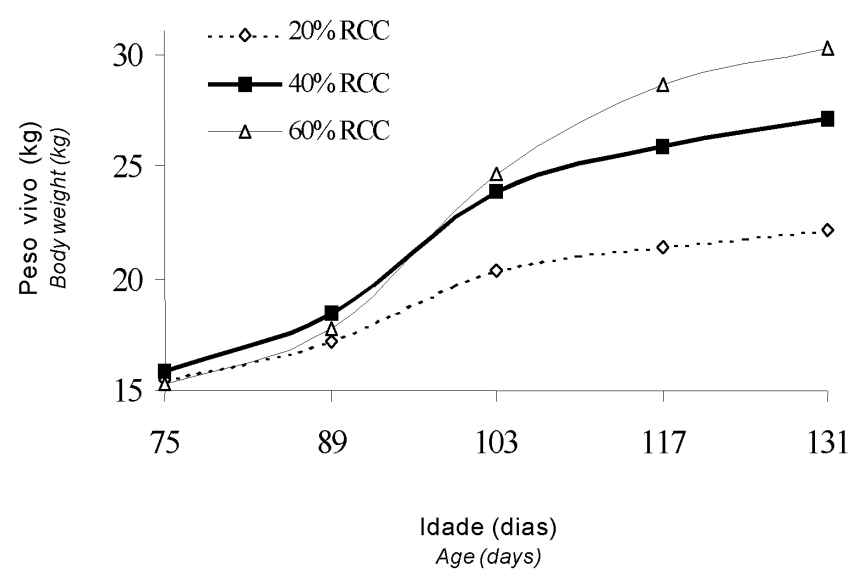

Figura 2 - Crescimento de cordeiros alimentados com dietas à base de silagem de milho com distintas proporções de ração concentrada comercial (RCC).

Figure 2 - Growth of lambs fed corn silage-based diets with increasing concentrate proportions (RCC).

matéria seca $\left(\mathrm{P}<0,01\right.$ e $\left.\mathrm{R}^{2}=0,99\right)$, provavelmente em decorrência de sua boa característica nutritiva. Tendência similar foi encontrada por Resende et al. (1994), com aumento linear significativo no consumo voluntário, ao se elevar o nível de energia digestível das dietas.

Os valores de ingestão de MS, nos níveis elevados de ração concentrada, foram adequados aos cordeiros em terminação, contudo, nas proporções mais baixas, não foram satisfatórios para um bom desempenho animal (NRC, 1985).

Quanto ao ganho de peso, houve efeito significativo entre as dietas com menores proporções de ração concentrada (Tabela 3), enquanto, nas dietas com elevada proporção de ração concentrada os ganhos médios diários de peso vivo não apresentavam diferença significativa. Isto evidencia que animais alimentados com silagem de girassol necessitam de maior complementação com ração concentrada para produzir resultados semelhantes aos alimentados com dietas à base de silagem de milho. As diferenças na constituição da parede celular (Tabela 1), na digestibilidade e no valor energético entre as dietas (Tabela 2), aliadas à menor ingestão voluntária, podem explicar este fato. Os animais alimentados com dietas à base de silagem de milho apresentaram ganhos diários de peso vivo mais elevados, em decorrência de sua melhor característica bromatológica, digestibilidade dos nutrientes e de seu conteúdo energético.

O acréscimo na proporção de ração concentrada resultou em aumento linear $\left(\mathrm{P}<0,01\right.$ e $\left.\mathrm{R}^{2}=0,92\right)$ no ganho de peso vivo diário dos cordeiros. Quando se administraram maiores proporções de ração concentrada (60\%), os ganhos foram adequados para cordeiros em terminação (NRC, 1985).

Para conversão alimentar (Tabela 3), houve diferença significativa entre as dietas, com valores mais elevados para as dietas à base de silagem de girassol. Contudo, nas dietas com maiores proporções de ração concentrada, não foi encontrada diferença significativa. Possivelmente, a composição bromatológica das silagens (Tabela 1) e sua digestibilidade pelos animais (Tabela 2) expliquem as diferenças entre as dietas.

O incremento na proporção de ração concentrada na dieta dos cordeiros acarretou diminuição linear significativa na conversão alimentar $\left(\mathrm{P}<0,05\right.$ e $\mathrm{R}^{2}=$ $0,88)$, comprovando que o aumento de nutrientes digestíveis pode melhorar esta variável. Os valores encontrados com os níveis elevados de ração concentrada foram adequados para esta categoria animal e mostra o potencial destes animais para conversão de alimentos de origem vegetal.

Os valores de ganho de peso diário reportados por Garcia et al. (2000), que trabalharam com borregos cruzados alimentados com dietas de alta energia, foram maiores que os observados neste estudo, embora os valores de CA naquele ensaio tenham sido 
superiores. Os valores de ganho de peso de cordeiros de raças de corte criados em confinamento, relatados por Ribeiro et al. (2003), foram similares aos encontrados neste estudo, para os cordeiros alimentados com silagem de milho com nível intermediário de ração concentrada.

\section{Conclusões}

Dietas à base de silagem de girassol têm valor nutritivo inferior às dietas à base de silagem de milho.

Cordeiros em crescimento alimentados com dietas à base de silagem de girassol apresentam desempenho inferior aos alimentados com silagem de milho.

Os animais alimentados à base de silagem de girassol necessitam de maior quantidade de ração concentrada para alcançarem desempenho similar ao dos alimentados com silagem de milho.

\section{Literatura Citada}

AGRICULTURAL AND FOOD RESEARCH COUNCIL - AFRC. Energy and protein requirements of ruminants. An advisory manual prepared by the AFRC Technical Committee on responses to Nutrients. CAB International, 1993. 159p.

ALMEIDA, M.F.; Von TIESENHAUSEN, I.M.E.; AQUINO, L.H. et al. Composição química e consumo voluntário das silagens de sorgo, em dois estádios de corte, girassol e milho para ruminantes. Ciência e Prática, v.19, n.3, p.315-321, 1995.

CARDOSO, R.C.; VALADARES FILHO; S.C.; SILVA, J.F.C. et al. Consumo e digestibilidades aparentes totais e parciais de rações contendo diferentes níveis de concentrado em novilhos F1 Limousin x Nelore. Revista Brasileira de Zootecnia, v.29, n.6, p.1832-1843, 2000.

CUNHA, E.A.; BUENO, M.S.; SANTOS, L.E. et al. Desempenho e características de carcaça de cordeiros Sufolk alimentados com diferentes volumosos. Ciência Rural, v.31, n.4, p.671-676, 2001.

GARCIA, I.F.F.; PEREZ, J.R.O.; TEIXEIRA, J.C. et al. Desempenho de cordeiros Texel X Bergamácia, Texel X Santa Inês e Santa Inês puros terminados em confinamento, alimentados com casaca de café como parte da dieta. Revista Brasileira de Zootecnia, v.29, n.2, p.564-572, 2000.

GONÇALVES, L.C.; TOMICH, T.R.; PEREIRA, L.G.R. Produção e utilização de silagens de girassol. In: SIMPÓSIO DE FORRAGICULTURA E PASTAGENS, 1., 2000, Lavras. Anais... Lavras: Universidade Federal de Lavras, 2000. p.203-236.

HENRIQUE, W.; ANDRADE, J.B.; SAMPAIO, A.A.M. Silagem de milho, sorgo, girassol e suas consorciações. II. Composição bromatológica. In: REUNIÃO ANUAL DA SOCIEDADE BRASILEIRA DE ZOOTECNIA, 35., 1998, Botucatu. Anais... Botucatu: Sociedade Brasileira de Zootecnia, 1998a. p.379-381.
HENRIQUE, W.; ANDRADE, J.B.; SAMPAIO, A.A.M. Silagem de milho, sorgo, girassol e suas consorciações. III. Coeficientes de Digestibilidade. In: REUNIÃO ANUAL DA SOCIEDADE BRASILEIRA DE ZOOTECNIA, 35., 1998, Botucatu. Anais... Botucatu : Sociedade Brasileira de Zootecnia, 1998b. p.382-384.

MCGUFFEY,R.K.; SCHINGOETHE, D.J. feeding values of a high oil variety of sun flowers as silage to lacttating dairy coows. Journal of Animal Science, v.63, n.7,p.1109-1113, 1980.

MERTENS, D.R. Regulation of forage intake. In: FAHEY JR., G. (Ed.). Forage quality, evaluation and utilization. Madison:American Society of Agronomy, 1994. p.450-493.

MIZUBUTI, I.Y.; RIBEIRO, E.L.A.; ROCHA, M.A. et al. Consumo e digestibilidade aparente das silagens de milho (Zea mays L.), sorgo (Sorghum bicolor ( L.) Moench) e girassol (Helianthus annuus L.). Revista Brasileira de Zootecnia, v.31, n.1, p.267-272, 2002.

NATIONAL RESEARCH COUNCIL - NRC Nutrient requirement of sheep. 6.ed. Washington, D.C.: National Academic of Sciences, 1985. 99p.

PEREIRA, O.G.; OBEID, J.A.; GOMIDE, J.A. et al. Produtividade de uma variedade de milho (Zea mays L.) e de três variedades de sorgo (Shorgum bicolor (L.) Moench) e o valor nutritivo de suas silagens. Revista da Sociedade Brasileira de Zootecnia, v.22, n.1, p.31-38, 1993.

RESENDE, F.D.; QUEIROZ, A.C.; FONTES, A.A. et al. Rações com diferentes níveis em detergente neutro na alimentação de bovídeos em confinamento. Revista da Sociedade Brasileira de Zootecnia, v.23, n.3, p. 23-30, 1994.

RIBEIRO, E.L.A.; SILVA, L.D.F.; ROCHA, M.A. et al. Desempenho de cordeiros inteiros ou submetidos a diferentes métodos de castração abatidos aos $30 \mathrm{~kg}$ de pesoo vivo. Revista Brasileira de Zootecnia, v.32, n.3, p.45-51, 2003.

RODRIGUES, P.H.M.; ALMEIDA, T.F.; MELOTTI, L. et al. Efeito dos inoculantes microbianos sobre a composição química e características fermentativas da silagem de girassol produzida em silos experimentais. Revista Brasileira de Zootecnia, v.30, n.6, p.169-175, 2001.

STATISTICAL ANALYSES SYSTEM - SAS. User's guide: statistics. 4.ed. Cary: 1990. 956p.

SCHNEIDER, P.H.; FLATT, W.P. The evaluation of feeds through digestibility experiment. Georgia: University of Georgia Press, 1975. 423p.

THOMAS, V.M.; MURRAY, G.A.; THACKER, D.L. Sunflower silage in rations for lactating holstein cows. Jouranl of Dairy Science, v.65, n.2, p.267-270, 1982.

VALDEZ, F.R.; HARISSON, J.H.; DEETZ, D.A. et al. In vivo digestibility of corn and sunflower intercropped as a silage crop. Journal of Dairy Science, v.71, n.7, p.18601867, 1988a.

VALDEZ, F.R.; HARRISON, J.H.; FRANSEN, S.C. Effect of feeding corn-sunflower silage on milk production, milk composition and rumen fermentatiomn of lactating dairy cows. Journal of Dairy Science, v.71, n.9, p.2462-2469, 1988b.

Recebido em: 12/05/03 Aceito em: 18/06/04 